\title{
Evaluation of Iron Supplementation Effects on Various Haematological Parameters in Pregnant Anemic Patients of Sargodha Region in Pakistan
}

\section{Dogar $\mathrm{MZ}^{1 *}$, Latif $\mathrm{I}^{2}$, Saba $\mathrm{A}^{2}$, Kanwal $\mathrm{S}^{2}$, Khan $\mathrm{AH}^{3}$, Khan $\mathrm{ZI}^{4}$ and Ahmad $\mathrm{K}^{4}$}

${ }^{1}$ Department of Biochemistry, Sargodha Medical College UOS, Sargodha, Pakistan

${ }^{2}$ Department of Chemistry, UOS, Sargodha, Pakistan

${ }^{3}$ Department of Pathology, SMC, UOS, Sargodha, Pakistan

${ }^{4}$ Department of Biological Sciences, University of Sargodha, Pakistan

\begin{abstract}
This study shows the beneficial role of iron to enhance various haematological parameters. Forty pregnant anemic women were selected at random from Sargodha region from the anti-natal outdoor patient department of DHQ Teaching Hospital Sargodha, Depending upon age they were subdivided into 02 Groups (Group- $1<30$ years \& Group- $2 \geq 30$ years age). They were given iron supplementation for a period of 3 months duration ( $1^{\text {st }}$ June to $31^{\text {st }}$ August 2012 ) in their $2^{\text {nd }}$ trimester period. They were asked to take oral iron supplementation $(150 \mathrm{mg}$ per day equivalent to $56 \mathrm{mg}$ of elemental iron) in the form of available branded medicine. Blood samples were collected before and after the treatment. The evaluation of haematological parameters showed that iron supplementation has positive effects on all haematological parameters. As Haemoglobin $(\mathrm{Hb})$ iron level raised from $8.2 \mathrm{~g} / \mathrm{dl}$ to $10 \mathrm{~g} / \mathrm{dl}$ in Group-1 and from $8.8 \mathrm{~g} / \mathrm{dl}$ to $9.7 \mathrm{~g} / \mathrm{dl}$ in Group-2. The Haemotoric (Hct) was increased from $32 \%$ to $37 \%$ in Group-1 and $33 \%$ to $36 \%$ in Group-2 while the RBCs counts were increased from $3.8 \times 10^{12} / \mathrm{L}$ to $4.5 \times 10^{12} / \mathrm{L}$ in Group-1 and from $3.9 \times 10^{12} / \mathrm{L}$ to $4.4 \times 10^{12} / \mathrm{L}$ in Group-2. The Mean Corpuscular Volume (MCV) was increased from $78.38 \mathrm{fl}$ to $81.17 \mathrm{fl}$ in Group-1 and from $79.46 \mathrm{fl}$ to $81.49 \mathrm{fl}$ in Group-2. The Mean Corpuscular Haemoglobin (MCH) was raised from $23.13 \mathrm{pg}$ to $25.76 \mathrm{pg}$ in Group-1 and $25.00 \mathrm{pg}$ $-26.13 \mathrm{pg}$ in Group-2 with the Mean Corpuscular Haemoglobin Concentration (MCHC) was increased from $30.17 \%$ to $32.58 \%$ in Group -1 and $31.64 \%$ to $33.50 \%$ in Group-2. The P value showed that the rise in all the above values was statistically significant $(P<0.05)$.

The Platelets and TLCs counts remained unchanged after iron therapy as their $p$ value was greater than 0.05 . To find out any change in body defensive system, the Total Lenclcocyto Count (TLC) and differential leucocytes count (DLCs) were also calculated. This shows that the TLCs were $8.91 \times 10^{9} / \mathrm{L}$ and $9.82 \times 10^{9} / \mathrm{L}$ in Group 1 and $8.98 \times 10^{9} / \mathrm{L}$ and $9.31 \times 10^{9} / \mathrm{L}$ in Group 2 before and after iron supplementation. However the $\mathrm{p}$ value $(>0.05)$ showed that the changes were no significant. This also showed that the neutrophils, eosinophils and monocytes remained unaffected after supplementations as the variation in these values were insignificant $(P>0.05)$ while the lymphocytes were increased from $26.50 \%$ to $29.50 \%$ in Group-1 and $26.50 \%$ to $28.78 \%$ in Group-2 and the change was statistically significant $(p=0.00)$. This shows the significance of iron to raise the lymphocytes count in blood, in spite of the fact, the previous literature coat that the values usually decrease but not increase during pregnancy.
\end{abstract}

Keywords: Iron; Haematological; Anemic; Pakistan

\section{Introduction}

Pregnancy is associated with physiological changes that results in an increased plasma and red cells volume. It also leads to the reduction in circulating nutrient-binding proteins and micronutrients (e.g. iron, folic acid, and vitamin B12). The changes occurring in the body physiology coated in many developing countries of the world are associated with malnutrition, leading to micronutrient deficiency states, such as anemia. Pregnancy is a time period in which requirement of iron is greater than normal as compared to absorbable iron intake hence iron deficiency takes place. Most of the women start their Pregnancy with moderate or completely depleted iron reserves and the severity of the anemia is correlated with the amount of iron reserves presents [1]. In Pregnancy, there is a greater demand for iron to meet the requirement of increasing red blood cells and other quickly developing cells mass expansions in the mother. The fetal and placental blood and blood loss at delivery are other indications for providing extra iron in the second and third trimester of pregnancy. It is sometimes also associated with additional folic acid requirements. Actually, in condition like growth, menstruation and pregnancy, the body's requirements for iron are increased. During pregnancy, iron deficiency is greater because of the ability of fetus to extract its iron requirement in obligatory one way direction even from iron deficient mothers [2]. This may be provoked by poor absorption of iron due to unpleasant effects of pregnancy on the gastrointestinal tract, which include nausea and vomiting along with some other motility disorder like indigestion etc. [3]. However in developed countries, the occurrence of anemia during pregnancy is lower, about $20 \%$. Pregnancy causes a lot of physiological and hormonal changes where increase in plasma is more dramatic than red blood cell mass expansion. Therefore erythropoiesis, the hemoglobin concentration, the erythrocyte count and the haematocrit looks decrease during normal pregnancy.

Nutrient demand increase during the pregnancy to support fetal growth and maternal health. Iron requirements in pregnant women are approximately doubled than that of non-pregnant women [4]. Such increasing demands leads to a decline in iron stores during

*Corresponding author: Dogar MZ, Department of Biochemistry, Sargodha Medical College UOS, Sargodha, Pakistan, E-mail: postdoc233@yahoo.com

Received March 22, 2013; Accepted June 28, 2013; Published July 01, 2013

Citation: Dogar MZ, Latif I, Saba A, Kanwal S, Khan AH et al. (2013) Evaluation of Iron Supplementation Effects on Various Haematological Parameters in Pregnant Anemic Patients of Sargodha Region in Pakistan. J Environ Anal Toxicol 3: 179. doi:10.4172/2161-0525.1000179

Copyright: ( 2013 Dogar MZ, et al. This is an open-access article distributed under the terms of the Creative Commons Attribution License, which permits unrestricted use, distribution, and reproduction in any medium, provided the original author and source are credited. 
pregnancy and eventually can produce iron-deficient erythropoiesis and anemia because under such circumstances, it becomes difficult to achieve an iron balance .In developing countries the occurrence of iron deficiency in pregnant women is even more, about $30-40 \%$ [5]. In addition deficiency anemia has a negative effect on fetus mental development and behavior and it may be an additional causative factor for development of brain with adult cardiovascular problems [6]. Previous studies provide evidence that maternal iron deficiency is responsible for preterm delivery and low birth weight [7]. Possibly pre-natal anemia is a main causative factor for maternal mortality in underdeveloped countries [8]. In some Asian countries like Indonesia and India high frequency of iron deficiency was reported in pregnancy, associated with high prenatal mortality rate [9]. During pregnancy body absorbs iron more effectively and iron is helpful to prevent the symptoms of tiredness, weakness, irritability and depression etc. A study conducted in India shows a positive relationship between iron supplementation and birth outcomes. Pregnant women commonly develop iron deficiency anemia because of increasing iron demand of the developing fetus and placenta and the increased blood circulating volume in the body during pregnancy [10].

A similar study to refer here in by Dogar et al. [11] and Dogar et al. [12], including the similar results of decrease in serum zinc levels after oral intake of $150 \mathrm{mg} /$ day equal to $56 \mathrm{mg}$ of elemental iron (ferrous sulphate) tablets. This positive correlation of hemoglobin concentrations with iron and a negative correlation with serum zinc levels and some other haematological parameters indicates that deficiencies of the two minerals were frequent and even harsher in anemic pregnant women. Large numbers of mortalities during pregnancy (e.g premature deliveries and infants with low birth weight) are due to iron deficiency. The worldwide anemia prevalence data shows that normal dietary intakes of iron in mother's milk are insufficient to meet up reserves and the infant weaned at this stage may increase intensity of iron deficiency. An exclusive unexplainable action of iron is its role in the neurologic development of the infant. The animal studies on iron functions clearly shows that iron deficiency leads to alterations in brain iron content, distribution, and metabolism [13].

Numerous studies have revealed a U-shape relationship between the level of hemoglobin $(\mathrm{Hb})$ and adverse pregnancy outcomes such as stillbirth, pregnancy induced hypertension, growth retardation etc. These are related with low blood $\mathrm{Hb}$ levels $(<11 \mathrm{~g} / \mathrm{L})$. Furthermore these risks increase even more when the level of $\mathrm{Hb}$ is above $13.2 \mathrm{~g} / \mathrm{dl}$. High level of $\mathrm{Hb}$ is responsible for increase in blood viscosity due to failure of plasma volume expansion [14]. So present study was conducted to check the effectiveness of available branded iron supplementation on various haemotological parameters in pregnant anemic patients of Sargodha region in Pakistan.

\section{Materials and Methods}

The subjects included in study were 40 pregnant women having $\mathrm{Hb}$ $(<11 \mathrm{~g} / \mathrm{dL})$ and of different age groups and were selected at random from Sargodha region in Pakistan. The hematological parameters used to investigate the anemia, were hemoglobin concentration and haematocrit value. The normal hemoglobin and the normal haematocrit cutoff levels for pregnant women used in this study were $\mathrm{Hb} \geq 11 \mathrm{~g} / \mathrm{dl}$ and Hct $\geq 33 \%$, respectively [5]. To assess the iron status of the subjects, serum iron value was used as a maker. Pregnant women below 30 years were categorized as Group-1 and those who were equal to or above 30 years were categorized as Group-2. All women were recommended iron tablets ( $150 \mathrm{mg}$ per day equivalent to $56 \mathrm{mg}$ of elemental iron) in their $2^{\text {nd }}$ trimester period. In order to enhance the $\mathrm{Hb}$ levels, for a period of 03 months, iron tablets were given in the form of available branded medicine Ferrous Sulphate and its effects were assessed on various hematological parameters in pregnant anemic women. Blood samples were collected at start (before the initiation of treatment) than after 03 months of treatment. The changes occurs in the level of RBCs, $\mathrm{Hb}$, $\mathrm{MCV}, \mathrm{MCH}, \mathrm{MCHC}$, Platelets counts, TLC and DLCs (different types of white cells), were recorded for comparison between the 02 different age groups.

All hematological parameters were estimated by an automated analyzer (Sysmex $k \times 21$ ), that measures the numbers as well as types and variety of cells available the blood. It takes a very small amount of haparinized blood sample which passes through narrow tubes containing sensors, capable to calculate the numbers of cells passing through it. It can classify the types of cells as well. Light detectors are used for the measurement of electronic impedance during passage through the haematology analyzer [15].

To compare the means, the Statistical analysis used in present study included paired sample t-test. The $p$ values were obtained to find the significance of each parameter. Mean, median, mode, range and standard deviations (SD) were calculated for each haematological parameters. All data was analyzed by using the SPSS program (SPSS Inc. Statistical Package for Social Science, Version 16, SPSS Inc, USA).

\section{Results}

The results obtained for different haematological parameters are shown below for comparison of changes in both the groups. The RBCs increases significantly and the trend was similar in both the groups. A statistically significant increase $(\mathrm{P}<0.05)$ in $\mathrm{RBC}$ count was found in both the groups after supplementation. It also showed an increase in $\mathrm{Hb}$ level after supplementation. This increase was very prominent in both the groups and hemoglobin percentage improved to a greater extent in anemic pregnant women after oral iron therapy. This increase was highly significance. It may be related to the increased rate of iron absorption that fulfils the depleted iron stores in the body of anemic pregnant women.

Table 1 shows the levels of RBCs count before and after iron supplementation in both the groups.

Table 2 shows a positive effect of iron supplementation on Hct values. The Hct rise was prominent in the both groups but the rise was more prominent in Group-1 as compare to Goup-2. A statistically significant increase $(\mathrm{P}<0.05)$ in Hct and MCV occurred in both groups after iron supplementation. The Haematocrit value decreases during pregnancy due to increasing plasma volume, but iron supplementation has positive effects on Hct values, the $\mathrm{p}$ value was significant.

Regarding the $\mathrm{MCV} \& \mathrm{MCH}$, the results shows a significant change $(p<0.05)$. The MCV values in both the groups were changed after oral iron supplementation having P values in Group-1was 0.02 and Group-2 it was 0.03 respectively. An increase in MCV was from $78.3-81.8 \mathrm{fl} \pm$ to 80.4-81.4 $\pm \mathrm{fl}$ in Group-1 \& Group-2 before and after supplementation respectively. Regarding the $\mathrm{MCH}$ levels; the changes were more prominent in Group-2 $(\mathrm{p}=0.00)$ as compare to Group-1 $(\mathrm{p}=0.05)$ The values of $\mathrm{MCH}$ were increased from 23 to $25 \mathrm{pg}$ in Group 1 and 25 to 26pg in Group-2 before and after supplementation respectively. The results are shown in Table 2 above. Regarding the $\mathrm{MCH} \& \mathrm{MCHC}$ values, the results show an increase in $\mathrm{MCH}$ and $\mathrm{MCHC}$ after iron supplementation. The changes are more prominent in Group-2 as compared to Group-1. The results are shown in Table 3. 


\begin{tabular}{|c|c|c|c|c|c|c|c|c|}
\hline \multirow{3}{*}{$\begin{array}{c}\text { Statistical } \\
\text { parameters }\end{array}$} & \multicolumn{4}{|c|}{ Red blood cells Count $\times 10^{12} / \mathrm{L}$} & \multicolumn{4}{|c|}{ Haemoglobin g/dl } \\
\hline & \multicolumn{2}{|c|}{ Group-1 } & \multicolumn{2}{|c|}{ Group-2 } & \multicolumn{2}{|c|}{ Group-1 } & \multicolumn{2}{|c|}{ Group-2 } \\
\hline & Before & After & Before & After & Before & After & Before & After \\
\hline Mean & 3.81 & 4.51 & 3.93 & 4.42 & 8.23 & 10.03 & 8.85 & 9.77 \\
\hline Median & 3.84 & 4.52 & 3.80 & 4.49 & 8.300 & 10.00 & 8.85 & 9.95 \\
\hline Mode & 3.90 & 4.46 & 3.32 & 3.68 & 7.70 & 10.00 & 9.50 & 8.80 \\
\hline Range & 0.76 & 0.86 & 1.57 & 1.92 & 1.60 & 2.00 & 2.10 & 2.20 \\
\hline S.D & 0.21 & 0.26 & 0.49 & 0.63 & 0.52 & 0.64 & 0.77 & 0.71 \\
\hline T value & 2.97 & & 4.322 & & 19.851 & & 7.735 & \\
\hline P value* & 0.015 & & 0.001 & & 0.000 & & 0.000 & \\
\hline
\end{tabular}

${ }^{*} \mathrm{P}<0.05$ shows a significant change

Table 1: Comparison of RBCs \& Hb levels before and after iron supplementation in different age groups.

\begin{tabular}{|l|l|l|l|l|l|l|l|l|}
\hline $\begin{array}{c}\text { Statistical } \\
\text { parameters }\end{array}$ & \multicolumn{3}{|c|}{ Haematocrit(Hct) age \% } & \multicolumn{4}{c|}{$\begin{array}{c}\text { Mean Corpuscular } \\
\text { Volume(MCV) fl }\end{array}$} \\
\hline & \multicolumn{2}{|c|}{ Group-1 } & \multicolumn{2}{|c|}{ Group-2 } & \multicolumn{2}{c|}{ Group-1 } & \multicolumn{1}{c|}{ Group-2 } \\
\hline & Before & After & Before & After & Before & After & Before & After \\
\hline Mean & 32.79 & 37.65 & 33.10 & 36.33 & 78.38 & 81.17 & 80.46 & 81.49 \\
\hline Median & 32.85 & 38.33 & 33.30 & 36.50 & 79.10 & 80.50 & 80.20 & 81.50 \\
\hline Mode & 28.30 & 35.80 & 33.00 & 33.90 & 70.40 & 78.00 & 83.00 & 68.00 \\
\hline Range & 7.90 & 6.30 & 8.20 & 6.50 & 15.60 & 13.90 & 26.40 & 26.30 \\
\hline S.D & 2.69 & 2.08 & 2.24 & 1.80 & 5.30 & 4.66 & 7.88 & 7.80 \\
\hline T value & 8.551 & & 13.462 & & 2.728 & & 3.116 & \\
\hline P value $^{*}$ & 0.000 & & 0.000 & & 0.023 & & 0.008 & \\
\hline
\end{tabular}

${ }^{*} \mathrm{P}<0.05$ shows a significant change

Table 2: Comparison of HCT \& MCV levels before and after iron supplementation in different age groups.

\begin{tabular}{|l|l|l|l|l|l|l|l|l|}
\hline $\begin{array}{c}\text { Statistical } \\
\text { parameters }\end{array}$ & \multicolumn{3}{|c|}{$\begin{array}{c}\text { Mean Corpuscular } \\
\text { Haemoglobin (MCH)pg }\end{array}$} & \multicolumn{4}{c|}{$\begin{array}{c}\text { Mean Corpuscular } \\
\text { Haemoglobin Concentration } \\
\text { (MCHC)\% }\end{array}$} \\
\hline & \multicolumn{2}{|c|}{ Group-1 } & \multicolumn{2}{c|}{ Group-2 } & \multicolumn{2}{c|}{ Group-1 } & \multicolumn{2}{c|}{ Group-2 } \\
\hline & Before & After & Before & After & Before & After & Before & After \\
\hline Mean & 23.13 & 25.76 & 25.00 & 26.13 & 30.17 & 32.38 & 31.64 & 33.50 \\
\hline Median & 23.380 & 27.00 & 25.00 & 25.90 & 30.00 & 32.00 & 32.00 & 34.00 \\
\hline Mode & 24.00 & 27.00 & 24.00 & 25.00 & 30.00 & 32.00 & 32.00 & 34.00 \\
\hline Range & 8.50 & 9.50 & 6.20 & 6.90 & 3.00 & 4.00 & 3.00 & 6.00 \\
\hline S.D & 2.68 & 3.05 & 1.60 & 2.04 & 0.92 & 1.35 & 1.08 & 1.55 \\
\hline T value & 2.244 & & 3.369 & & 5.478 & & 5.953 & \\
\hline P value* & 0.052 & & 0.005 & & 0.000 & & 0.000 & \\
\hline
\end{tabular}

${ }^{*} \mathrm{P}<0.05$ shows a significant change

Table 3: Comparison of $\mathrm{MCH} \& \mathrm{MCHC}$ levels before and after iron supplementation in different age groups.

Regarding platelets count, the results in Table 4, show that there was no change by iron supplementation on platelets count. This remained unchanged as their $\mathrm{P}$ value was statistically insignificant $(\mathrm{P}>0.05)$. The results were variable as the mean values of platelets count were $256 \times 10^{9} / \mathrm{L}-251 \times 10^{9} / \mathrm{L}$ in Group 1 and were $285 \times 10^{9} / \mathrm{L}-274 \times 10^{9} / \mathrm{L}$ in Group-2 before and after supplementation respectively. The $\mathrm{P}$ value in Group- 1 shows a significant change $(\mathrm{p}=0.004)$ and the Goup- 2 shows a non-significant change $(\mathrm{p}=0.01)$.

Regarding the total Leucocytes Count (TLC), the major types of white blood cells are neutrophils, lymphocytes, monocytes, eosinophils, and basophiles. Each type plays a different role in protecting the body. The numbers of each type of white blood cells give important information regarding the defense system. Too high or too low values of different types of white blood cells can help to find out causes of diseases e.g. an infection, an allergic condition or a toxic reaction etc. A study conducted in Nigeria to find effects on haematological parameters in pregnant women reported that during pregnancy, WBCs were elevated. It was also found that leucocytes increase occur commonly in early pregnancy. This perhaps may be due to the start of an immune response in the fetus, achieved by a selective immunotolerance, immunosuppression and immunomodulation along with the development well-built antimicrobial immunity. These cause changes in differential leukocyte counts in pregnant ladies.

The data shows that iron supplementations do not change the TLC up to noticeable level. The Group-1 data shows a more significant increase that occurred after supplementations but the data of Group-2 showed a less significant rise in values after supplementation. The results are shown in Table 4.

The results in Table 5 shows that there was no effect of iron supplementation on neutrophils and eosinophils numbers, these remained unchanged as the $\mathrm{P}$ values were statistically insignificant $(\mathrm{P}>0.05)$. There was no noticeable change in both the groups. The Table also showed that iron supplementation has not affected neutrophils counts, as the mean values in both groups were same. Apparent increase in Group-2 was statistically insignificant. Some other studies also argue that iron does not affect granulocytes in circulation but affect their growth only in bone marrow. Regarding the Eosinophils results shows that eosinophils count in both the groups also remain changed by iron supplementations. Referring to other previous studies the differential leucocytes count during pregnancy, it was reported in number of studies that WBCs increases in pregnancy because the immune response of body to allergens, in fetus, develops during this period. Its evaluations were used to find changes after iron supplementation, but results show no significant change in eosinophils levels.

Regarding the Lymphocytes Counts, the results in Table 6 shows that values of lymphocytes in both the groups were increased by iron supplementations and the increase was statistically significant $(\mathrm{P}<0.05)$. Lymphocytes Counts in Group- 1 were $26.5 \%$ and $29.5 \%$ and in Group-2, these were $26.5 \%$ and $28.7 \%$, before and after supplementations respectively. The $p$ values of both the groups were highly significant 0.000 .

Regarding the Monocytes Counts the data shows that monocytes do not change significantly after supplementations. Both group shows same values which were statistically insignificant for both the groups; Group $-1(p=0.77)$ and for Group-2(p=0.69). The mean values of monocytes counts were changed from 7.0 to $7.1 \%$ in Group 1 and 7.1 to 7.2\% Group-2, before and after supplementation respectively.

Results of present study show that iron supplementation has been increased the blood Lymphocytes significantly after supplementations. The Basophils and Neutrophils count were found to be high before supplementation and these values remains unaffected by iron supplementations.

\section{Discussion}

A similar study conducted by Shumaila and Iqbal [16], showed similar results. A significant increasing trend in $\mathrm{Hb}$ level was found by oral iron supplementation after fourth, eighth and twelveth week of treatment A significant increase in RBCs counts was also observed $(\mathrm{p}<0.01)$, its value was increased from $3.65 \times 10^{12} / \mathrm{L}$ to $4.28 \times 10^{12} / \mathrm{L}$ after iron supplementation.

According to our study iron supplementation also raises the RBCs values to a significant level. Another study shows similar results, which reveals a significant raise in $\mathrm{Hb}$ level in anemic patients with $\mathrm{p}$ value of 


\begin{tabular}{|c|c|c|c|c|c|c|c|c|}
\hline \multirow[t]{3}{*}{$\begin{array}{c}\text { Statistical } \\
\text { parameters }\end{array}$} & \multicolumn{4}{|c|}{ Platelets count $\times 10^{9} / \mathrm{L}$} & \multicolumn{4}{|c|}{$\begin{array}{c}\text { Total Leucocytes } \\
\text { Count(TLCs) } \times 10^{9} / \mathrm{L}\end{array}$} \\
\hline & \multicolumn{2}{|c|}{ Group-1 } & \multicolumn{2}{|c|}{ Group-2 } & \multicolumn{2}{|c|}{ Group-1 } & \multicolumn{2}{|c|}{ Group-2 } \\
\hline & Before & After & Before & After & Before & After & Before & After \\
\hline Mean & 256.70 & 251.60 & 285.71 & 274.07 & 8.91 & 9.02 & 8.98 & 9.31 \\
\hline Median & 255.50 & 253.00 & 292.50 & 286.00 & 8.67 & 8.80 & 8.75 & 9.05 \\
\hline Mode & 210.00 & 204.00 & 312.00 & 206.00 & 8.50 & 10.00 & 7.70 & 8.00 \\
\hline Range & 90.00 & 94.00 & 133.00 & 139.00 & 2.10 & 2.00 & 4.00 & 4.30 \\
\hline S.D & 29.60 & 28.91 & 37.66 & 40.07 & 0.81 & 0.84 & 1.34 & 1.47 \\
\hline T value & 0.826 & & 1.390 & & 3.911 & & 2.867 & \\
\hline P value* & 0.430 & & 0.188 & & 0.004 & & 0.013 & \\
\hline
\end{tabular}

${ }^{*} \mathrm{P}<0.05$ shows a significant change

Table 4: Comparison of Platelets count \& TLCs before and after iron supplementation in different age groups

\begin{tabular}{|l|l|l|l|l|l|l|l|l|}
\hline $\begin{array}{c}\text { Statistical } \\
\text { parameters }\end{array}$ & \multicolumn{3}{|c|}{ Neutrophils (\%) } & \multicolumn{3}{c|}{ Eosinophils (\%) } \\
\hline & \multicolumn{2}{|c|}{ Group-1 } & \multicolumn{1}{c|}{ Group-2 } & \multicolumn{2}{c|}{ Group-1 } & \multicolumn{1}{c|}{ Group-2 } \\
\hline & Before & After & Before & After & Before & After & Before & After \\
\hline Mean & 66.23 & 66.90 & 66.56 & 65.28 & 3.52 & 3.98 & 3.50 & 3.64 \\
\hline Median & 65.50 & 66.50 & 68.00 & 63.50 & 3.50 & 4.00 & 3.50 & 4.00 \\
\hline Mode & 65.00 & 69.00 & 68.00 & 60.00 & 3.00 & 4.00 & 3.00 & 4.00 \\
\hline Range & 5.50 & 6.00 & 15.10 & 21.00 & 3.00 & 2.60 & 4.00 & 2.00 \\
\hline S.D & 1.76 & 2.23 & 4.37 & 6.54 & 0.86 & 0.85 & 1.16 & 0.63 \\
\hline T value & 1.34 & & 0.71 & & 1.24 & & 0.56 & \\
\hline P value* & 0.210 & & 0.486 & & 0.245 & & 0.583 & \\
\hline
\end{tabular}

${ }^{*} \mathrm{P}<0.05$ shows a significant change

Table 5: Comparison of Neutrophils \& Eosinophils levels before and after iron supplementation in different age groups.

\begin{tabular}{|l|l|l|l|l|l|l|l|l|}
\hline $\begin{array}{c}\text { Statistical } \\
\text { parameters }\end{array}$ & \multicolumn{3}{|c|}{ Lymphocytes (\%) } & \multicolumn{3}{c|}{ Monocytes (\%) } \\
\hline & \multicolumn{2}{|c|}{ Group-1 } & \multicolumn{2}{c|}{ Group-2 } & \multicolumn{2}{c|}{ Group-1 } & \multicolumn{1}{c|}{ Group-2 } \\
\hline & Before & After & Before & After & Before & After & Before & After \\
\hline Mean & 26.50 & 29.50 & 26.57 & 28.78 & 7.09 & 7.05 & 7.11 & 7.21 \\
\hline Median & 27.50 & 30.00 & 25.50 & 28.50 & 7.00 & 7.00 & 7.00 & 7.00 \\
\hline Mode & 19.00 & 32.00 & 19.00 & 32.00 & 7.00 & 7.00 & 7.00 & 7.00 \\
\hline Range & 16.00 & 13.00 & 15.00 & 16.00 & 4.00 & 4.00 & 7.00 & 7.00 \\
\hline S.D & 4.94 & 4.17 & 5.27 & 5.07 & 1.11 & 1.21 & 1.92 & 2.35 \\
\hline T value & 7.115 & & 5.252 & & 0.290 & & 0.40 & \\
\hline P value* $^{*}$ & 0.00 & & 0.00 & & 0.77 & & 0.69 & \\
\hline
\end{tabular}

${ }^{*} \mathrm{P}<0.05$ shows a significant change

Table 6: Comparison of Lymphocytes \& Monocytes counts before and after iron supplementation in different age groups.

0.001 after iron supplementation relative to non supplementation. The increased of $\mathrm{Hb}$ was $1.00 \pm 0.013 \mathrm{~g} / \mathrm{dL}$ [17]

Kuizon et al. [18], stated the positive role of iron supplementations to improve the haematological status. They treated the anemic pregnant ladies with $195 \mathrm{mg}$ crude iron per day and found a significant increase in $\mathrm{Hb}$ and Hct levels. Another similar study was conducted on pregnant anemic Saudi women to assess anemia and response of iron therapy in anemia. Changes were noticed during the iron supplementation on 30 pregnant women after 12 weeks. The haemoglobin $(\mathrm{Hb})$, haematocrit and serum ferritin concentration were calculated and compared with pre-supplement levels. A significant increase in all the parameters was observed after treatment $(\mathrm{p}<0.05)$. These results signify that daily iron supplementation in pregnancy (associated with iron deficiency anaemia) increases different haematological parameters but interesting thing to coat was that even after 12 weeks of iron supplementation, fail to normalize their blood iron levels. It remains lower even after delivery [16].
A significant change in $\mathrm{Hct}$ concentration $(\mathrm{P}<0.01)$ during pregnancy was noted in saudi women in their first trimester (35.67 $\pm 2.13 \%$ ) but the Hct of the mothers were increased in the second trimester of pregnancy to $33.01 \pm 2.99 \%$ [19]. The present study shows a significant increase in $\mathrm{MCV}, \mathrm{MCH}$ and $\mathrm{MCHC}$ after oral iron treatment.

A study for comparison showed that Haematocrit $(\mathrm{Hct})$ values in Pakistani young ladies were decreased up to $35-32 \%$ in normal pregnant women while by iron supplementation, these do not decrease, rather increase to a significant level $[11,12]$. Similarly results in another study show an increase in $\mathrm{Hb}$ and $\mathrm{MCV}$ after 5 weeks of treatment with oral iron supplementation in pregnant anemic women. Increase in the $\mathrm{Hb}$ level was from 7.5 to $11 \mathrm{~g} / \mathrm{dl}$ and increase in MCV was from 65 to $75 \mathrm{fl}$. Both the parameters showed statistically significant increase $(\mathrm{p}<0.05)$ [20]. It is found in previous studies that neutrophil count increases during iron deficiency that may be caused by changes in apoptotic response, lower oxidative burst and anti oxidant product synthesis resulting in an increased neutrophils life span. In addition, patients affecting from iron deficiency anemia have lower neutrophil phagocytic activity. Thus the increased granulocyte cell count in iron deficiency anemia patients could compensate for the reduced phagocytic capacity [21].

Regarding the platelets count, it is a common observation that the platelets commonly changes during pregnancy and because of haemodilution, mostly a decreasing trend are observed in pregnancy. This trend is even more common in those women who had low platelets levels prior to becoming pregnant and may be more prominent with passage of pregnancy. The gradual change continues in $2^{\text {nd }}$ to $3^{\text {rd }}$ trimesters. A platelet level below $150 \times 10^{9} / \mathrm{L}$ is considered low indicating a condition requires treatment. Higher platelets levels during pregnancy may be, generally a reactive response to the pregnancy and do not usually suggest a clinical problem [22]. Another study to be mentioned here is a white blood cell culture study that showed a positive effect of iron on lymphocyte proliferation [23]. Other studies also report that iron supplementation provoke an increase in $\mathrm{T}$ lymphocyte percentage [24].

\section{Conclusion}

Present study shows a significant increase in lymphocytes after iron supplementations. Furthermore the values of lymphocytes at start were comparatively low that may be due to anemia in pregnancy. This may be related to positive relationship between lymphocytes count and serum iron status. However these results are not compatible to already completed work by Ali et al. [21], who concluded that iron deficiency anemia is accompanied with an increased granulocyte along with decreased lymphocyte count. They reported lower T lymphocyte percentage in iron deficient anemic patients. The reasons of lymphocytes decline in iron deficiency coated in that study were inhibition of lymphocyte production with improved lymphocyte destruction. This study also showed that granulocyte count was significantly increases in iron deficient patients. When iron supplementation is done in the pregnant ladies, the effect may be opposite as depicted in the present study, indicating that iron has important positive effects on different white cells counts and functions.

\section{References}

1. Yaqoob N, Abbasi SM (2002) Nutritional iron deficiency in our population. J Col Physicians Surg Pak 12: 395-397

2. Breymann C; Anaemia Working Group (2001) Current aspects of diagnosis and therapy of iron deficiency anemia in pregnancy. Praxis 90: 1283-1291. 
Citation: Dogar MZ, Latif I, Saba A, Kanwal S, Khan AH et al. (2013) Evaluation of Iron Supplementation Effects on Various Haematological Parameters in Pregnant Anemic Patients of Sargodha Region in Pakistan. J Environ Anal Toxicol 3: 179. doi:10.4172/2161-0525.1000179

3. Breymann C (2002) Iron deficiency and anaemia in pregnancy: modern aspects of diagnosis and therapy. Blood Cells Mol Dis 29: 506-516.

4. Felt BT, Lozoff B (1996) Brain iron and behavior of rats are not normalized by treatment of iron deficiency anemia during early development. J Nutr 126 : 693-701.

5. McLean E, Cogswell M, Egli I, Wojdyla D, de Benoist B (2009) Worldwide prevalence of anaemia, WHO Vitamin and Mineral Nutrition Information System, 1993-2005. Public Health Nutr 12: 444-454.

6. Beard JL (2000) Effectiveness and strategies of iron supplementation during pregnancy. Am J Clin Nutr 71: 1288S-1294S.

7. Cogswell ME, Parvanta I, Ickes L, Yip R, Brittenham GM (2003) Iron supplementation during pregnancy, anemia, and birth weight: a randomized controlled trial. Am J Clin Nutr 78: 773-781.

8. Nisar N, White F (2003) Factors affecting utilization of antenatal care among reproductive age group women (15-49 years) in an urban squatter settlement of Karachi. J Pak Med Assoc 53: 47-53.

9. Ashraf M, Sheikh NH, Sheikh AH, Yusuf AW (2001) Maternal mortality. A 10year study at Lady Wallington Hospital, Lahore. Ann King Edward Med Coll 7: 205-207.

10. Auerbach M, Goodnough LT, Picard D, Maniatis A (2008) The role of intravenous iron in anemia management and transfusion avoidance. Transfusion 48: 9881000.

11. Dogar MZ, Ashraf M, Yaqoob M, Sharif N, Iqbal M, Hashmi AS (1995) Effect of high doses of iron supplementation on serum zinc levels. Post Graduate Med J 6: 43-46.

12. Dogar MZ, Ashraf M, Saeed M, Ali M, Yaqoob M, Hashmi AS, Chaudhry ZA (1997) Micromineral status; Evaluation of serum iron and zinc in young healthy individuals. The Professionals Med J 3: 286-291.

13. Beard JL, Connor JD, Jones BC (1993) Brain iron: location and function. Prog Food Nutr Sci 17: 183-221.
14. Stephansson O, Dickman PW, Johansson A, Cnattingius S (2000) Maternal hemoglobin concentration during pregnancy and risk of stillbirth. JAMA 284: 2611-2617.

15. Jones AR, Twedt D, Swaim W, Gottfried E (1996) Diurnal change of blood count analytes in normal subjects. Am J Clin Pathol 106: 723-727.

16. Khalid S, Ahmad SI (2012) Correction of iron deficiency anemia in pregnancy and its effects on superoxide dismutase. Pak J Pharm Sci 25: 423-427.

17. Sloan NL, Jordan E, Winikoff B (2002) Effects of iron supplementation on maternal hematologic status in pregnancy. Am J Public Health 92: 288-293.

18. Kuizon MD, Platon TP, Ancheta LP, Angeles JC, Nunez CB, et al. (1979) Iron supplementation studies among pregnant women. Southeast Asian J Trop Med Public Health 10: 520-527.

19. Al-Toub M (2006) Study of Serum Ferritin and Other Haematological Parameters in Pregnancy. Jouralovo 14-27.

20. Khurshid SR (2003) Intravenous personal communication iron sucrose complex therapy in iron deficiency anemia in the pregnant women. Departments of Obstetrics/Gynecology and Medicine Shifa College of Medicine and Shifa International Hospital, Islamabad. Domas.

21. Ali O, Muzaffer C (2011) Evaluation of leucocyte and its subgroups in iron deficiency anemia. International Journal of Medicine and Medical Sciences 3 . 135-138.

22. Sejeny SA, Eastham RD, Baker SR (1975) Platelet counts during norma pregnancy. J Clin Pathol 28: 812-813.

23. Javaid MT (2011) A study on iron deficiency anemia and hematological difference around delivery in women of different socioeconomic and different age groups. Medical Journal of Islamic Academy of Sciences 14: 151-160.

24. Moraes-de-Souza H, Kerbauy J, Yamamoto M, da-Silva MP, dos-Santos MR (1984) Depressed cell-mediated immunity in iron-deficiency anemia due to chronic loss of blood. Braz J Med Biol Res 17: 143-150. 